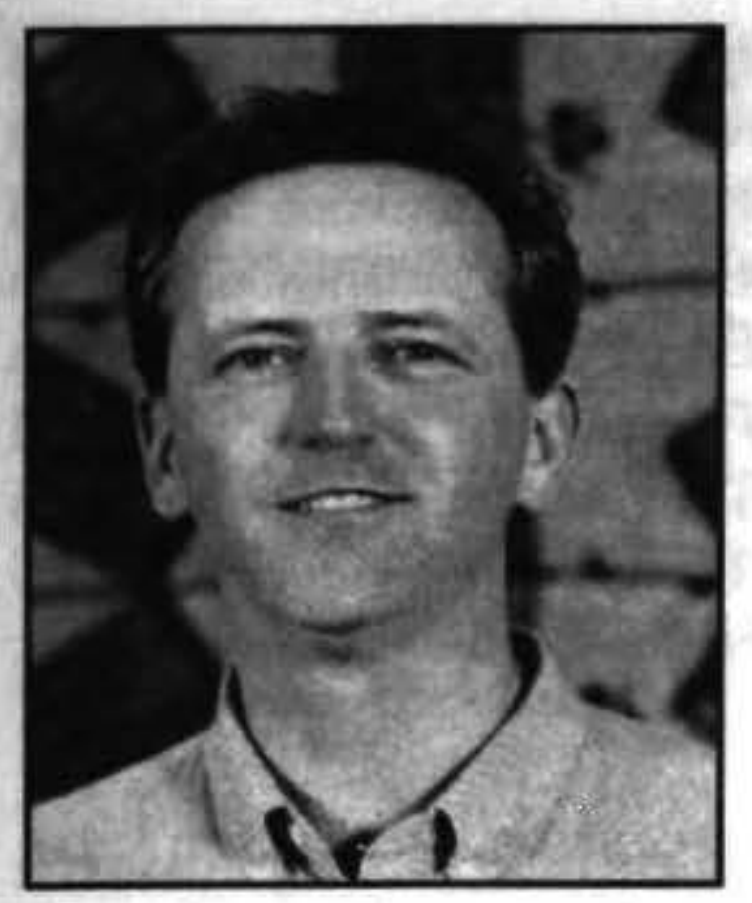

\title{
OCCUPATIONAL SICKNESS AND COMPENSATION: TWO NEW ZEALAND CASE STUDIES
}

\author{
Kevin Dew \\ Department of Public Health \\ Wellington School of Medicine
}

Abstract

This paper explores the process of seeking compensation for occupational illness under a no-fault accident insurance scheme. It uses two case studies, the first of firefighters who attended a fire at a chemical storage depot, the second of timbermill workers who worked with pentachlorophenol, to illustrate how science can be used to deny compensation to sick and dying workers. The paper suggests that science can be co-opted and used to support business and state interests against workers, and that this ideological support is increasingly hidden behind the development of 'objective' systems of assessing compensation claims.

\section{Keywords: Compensation, occupational illness, insurance claims}

New Zealand has, since 1974, had a no-fault response to adverse events that have been associated with injuries. Civil claims for damages arising from personal injury by accident were abolished and so employers could no longer be sued for workplace accidents.

Not only is personal injury compensatable under the Act, whether suffered inside our outside the workplace, but also occupational diseases, or more specifically, disease due to the nature of a person's employment (Accident Compensation Commission 1976: 11). However, as there is no compensation for sickness arising from other causes, some mechanism must be found to differentiate sickness caused from something outside the workplace, and sickness caused by something within the workplace. This becomes particularly important in what are known as gradual process claims, such as some cases of chemical poisoning where the cause may be disputed, and where eligibility criteria become important sites of dispute.

The Law Commission (Law Commission 1988:xi) argued that "for hiśtorical and pragmatic reasons, sickness incapacities were not included in the new comprehensive scheme". They go on to suggest that "clearly the demarcation is anomalous. It is the kind of situation which gives hard emphasis to what has been called the inequality of luck". This paper explores how this inequality of luck impacts upon workers suffering from conditions, the cause of which is disputed. Attempts have been made to develop objective criteria to judge eligibility, and science is seen as an adjudicator in these situations. The choices for scientists are to use a balance of probabilities approach when confronted with uncertainty, or to base eligibility upon certain proof of sickness caused by a worker's employment.

The following case studies explore the assumptions be- hind the decision to pursue "certainty" as the acceptable criteria. Certainty is in quotes, as it will be seen that to find that sickness is related to non-work agents requires a much lower level of proof than to find sickness as caused by workplace events. In other words, there is a double standard employed, where science can be co-opted to perpetuate injustices.

The following case studies of workers making claims that their sickness was work-related - the case of the ICI firefighters and the case of timbermill workers using pentachlorophenol (PCP) - indicates some interesting parallels in the working out of science-related health controversies under a no-fault insurance system. These cases also show that there has been a movement over time where 'objective' standards have been established so that disputes over gradual process claims can be settled more quickly. Although the 'objective' standards are promoted as offering a fair assessment of claims in cases where there is uncertainty, these standards appear to actually remove the notion of assessment on the basis of a balance of probabilities. In their stead, they reinforce a notion that claims can only be successful where they are firmly based on stringent standards of evidence.

\section{The ICI Fire}

The ICI fire took place at ICI's Riverview store in Mt Wellington on December 21, 1984. The New Zealand Fire Service extinguished the fire using complements of up to 86 firefighters. 141 firefighters attended the actual fire on that day, with a total of 340 being involved in the firefighting and subsequent clean up of the site and the equipment used (Elias et al. 1990:1). Whilst the fire was being fought firefighters began to complain of burning sensations on their feet and legs, and 34 firefighters sustained immediate injuries in the form of skin rashes. Long- 
term effects were also reported by the firefighters. By 1990,214 firefighters reported health problems, the majority with an onset since the ICI fire. Spouses of the firemen reported more problems with their partners health than the firemen concerned (Elias et al. 1990:23), possibly indicating an under-reporting issue.

The section of the warehouse that was destroyed by the fire contained an assortment of chemicals and the packaging materials would combust to generate a range of toxic products that would be present in the smoke. The fire would have produced a wide range of virtually unidentifiable by-products (New Zealand Fire Service Commission 1985:40), thus exposing the firefighters to many respiratory and systemic irritants. Out of this range of toxic substances one gained most attention-dioxin. Dioxin may arise in the combustion of chlorine and can occur as a byproduct of 2-4-5 T (Glass 1985:9), and both of these products were stored at the warehouse.

Following the a number of reports were completed, culminating in the release of the Elias Commission report to the Minister of Health on the health consequences of the ICI fire in 1990. It was apparent that the firefighters suffered from an array of symptoms (such as skin rashes, respiratory problems, concentration difficulties and so on), but relating symptoms to exposure to particular chemical was not a simple matter. One occupational physician noted that 'Because of the complex nature of pyrolysis it is seldom possible to identify one particular chemical as the cause of the symptom-complex... which may develop among the exposed' (Glass 1985:7). In addition the biologically active compound in the production of intoxication syndrome may be at such low concentrations that it may not be detectable by customary techniques. The Elias Commission in its final report ignored these difficulties as it dismissed chemical intoxication as a source of the firefighters ' troubles in favour of a psychological explanation.

The Elias Commission appointed a medical practitioner to investigate the health of the firefighters and a psychiatric specialist to provide a report on the psychiatric and psychological impact of the fire and its aftermath on firefighters. An epidemiological study carried out by the Elias Commission showed that compared to a control group, ICI firefighters had significantly higher self-reporting of health problems, poorer neuro-psychological tests, and a higher incidence of ongoing skin complaints and central nervous system symptoms (Elias et al. 1990:30). The Commission however saw major problems in such a study in terms of ascribing environmental causes of disease due to the long latent period, lack of exposure data, other confounding causes of any problems, recall bias, and problems of finding normative controls.

The Elias Commission report concluded that although the firefighters' symptoms were real and not imaginary, and although the firefighters suffered symptoms from exposure to toxins at the time of the fire, the symptoms that the firefighters continued to experience were due to stress and anxiety and should improve with the alleviation of that anxiety (Elias et al. 1990:9). The Commission concluded that 'there is no known toxicological justification' for an explanation of chronic skin or central nervous system symptoms experienced by firefighters following the ICI fire (Elias et al. 1990:97). Thus the Commission based its findings on the notion that there was not enough information available to confirm or deny this hypothesis, therefore it was rejected.

In contrast to the dismissal of chemical toxicity as a cause of the firefighters' symptoms, the Elias Commission accepted the psychiatrist's report, despite its low level of rigour. The psychiatrist's report criticises an academic ecologist and Greenpeace for their role in creating anxiety. It highlights the problems of a diagnosis of neurotoxicity and the lack of international standards for such tests. It looks at past studies which concluded that fear and anxiety may have contributed to symptoms in other cases where symptoms developed after handling chemicals. It takes a very small study involving 11 Australians diagnosed with post-traumatic stress disorder as supporting evidence for the relative unimportance of the stressful event as compared to prior psychological problems. Parsons 'sick role' is utilised to provide a concept that explains the firefighters problems, and other studies are cited which concluded that "disability following a working accident was primarily motivated by financial gain' (Elias et al. 1990:280). Reports are cited which link firefighters' health problems to levels of stress that they experience. The psychiatrist finds of great interest an incident of a fire involving pesticides, herbicides and insecticides where no firemen were hurt! (Elias et al. 1990:285). Therefore the conclusion is that the symptoms are a result of 'chronic and unfortunate stress' (Elias et al. 1990:291). It is on the basis of these loosely associated ideas that the Elias Commission drew their conclusion.

In their recommendations to deal with the 'anxiety' suffered by the firefighters, the Elias Commission proposed an extension of the activities of the occupational health service and that a way should be found to distance this service from management as firefighters were not making much use of it. The occupational health service should 'provide education in skin hygiene and treatment' to those firefighters who continued to suffer skin rashes (Elias et al. 1990:109). Psychological counselling should be provided to all of those firefighters who seek it for the effects of stress. It also proposed that all firefighters should undergo a number of medical tests at regular intervals.

These recommendations meant that the firefighters were to be increasingly subjected to medical surveillance that could lead to firefighters losing employment due to medical criteria. This outcome parallels Turner's Foucauldian analysis of lobbying for safety legislation by workers in the mining industry. In that particular instance the lobbying meant increasing losses of autonomy by the workers, and as safety legislation failed this led to further legisla- 
tion that increased the power of management (Turner 1989). Nelkin and Tancredi argue that there are incentives to test for the 'hypersusceptible' individual in the workplace, as there would be no need to change the workplace to make it safer - but attempt to identify and exclude the workers most susceptible (Nelkin and Tancredi 1994). The influence of this type of argument can be seen in the Elias Commission report, where firefighters were constructed as overly anxious individuals and in need of better hygiene regimes.

What this case illustrates is that criterion for accepting a particular agent as causal is flexible. In reality cause could derive from anxiety, from chemical A, B C, from dioxin, or from any series of interactions between these. But the standard of proof had to be that of certainty if the state was to pay out, but a lower level of certainty was used to diagnose anxiety as the cause of firefighters' problems. In essence, there are elaborate mechanisms that give the semblance of rigorous analysis in order produce an outcome that was favourable to all except the victims of injury.

\section{PCP and Timbermill Workers}

There are many similarities between the firefighters case and the following case study of timbermill workers. One significant difference is that by the 1990 s new 'objective' criteria had been developed to assess cases of possible occupational illness. The following case illustrates how these 'objective' criteria may also reinforce injustices.

Pentachorophenol (PCP) was extensively used in timbermills in New Zealand from the 1960 s to 1988 , although by the 1940 s experimental evidence started to accumulate about its toxicity to humans. It was mainly used as an antisapstain agent in the treatment of radiata pine. Sapstain is a fungal agent that infects freshly sawn timber. Over a 40 year period an estimated 5000 tonnes of PCP were used, making New Zealand amongst the heaviest per capita users of PCP in the world (Stevenson 1992), although it ceased being used in Sawmills from 1988. Growing local and international concerns over PCP contamination led to the chemical being de-registered for sale in New Zealand in December 1991,

Sawmill workers were exposed to PCP particularly when timber was graded and sorted Many of the workers suffered a variety of ill health effects which they later believed were related to PCP exposure, the Wood Industries Union registering 400 such workers. PCP contamination can cause an array of symptoms including fever, fatigue, weight loss, nausea and mood swings (Occupational Safety and Health Service 1996). Commercial or technical grades of PCP used in New Zealand also contained toxic impurities created during manufacture, including dioxins and furans (Bingham 1992).

In December 1990 a National Task Group (NTG) was set up which reported on potentially contaminated sawmill and timber treatment sites (National Task Group 1992). The Group's task was to assess the extent of PCP contaminated sites and advise government and industry on policies concerning liability, standards and clean-up. The NTG found that there were approximately 400 timbermill sites where PCP was used.

In terms of workers who might be affected by PCP, the NTG report stated that even full scale epidemiological studies would be unlikely to distinguish cases of chemical exposure from symptoms arising from such things as lifestyle and consumption behaviour impacts, hereditary conditions, and exposure to chemicals outside of the workplace. Obstacles to achieving scientific validation for the workers' complaints were immense and include the fact that it cost \$NZ1500 to measure dioxin levels in one individual. The procedure of taking one litre of blood required to measure dioxin can be too stressful for sick workers. Many of the sickest workers have already died, possibly eliminating the most seriously contaminated from any study. Even if high blood dioxin levels are found, this does not establish that the dioxin causes the symptoms. To complicate the picture further, dioxin may not be causing their problems - some other chemical or combination/ interaction of chemicals may be the culprit. Current scientific techniques may not be able to establish cause in these situations.

As with the ICI fire, the dispute over the cause of the workers' health problems is a clash between the 'balance of probabilities' approach and the 'beyond all reasonable doubt's approach (Jacques 1992:40). The National Task Group adhered to very strict definitions of scientific standards of certainty and proof, as opposed to looking at the balance of evidence. This was in part an outcome of its brief, which was to minimise the risks of further exposure to PCP. The NTG was not able to take up issues that were the domain of other departments, such as the Ministry of Health or the ACC. However, the point here is that when it comes to dealing with the workers' health, the principle adhered to has been the 'beyond all doubt' approach. If scientific validation is the sole criteria of legitimation, it can be an insurmountable obstacle for workers and others hoping to gain legitimation for their complaints (Dew 1999).

A later report commissioned by the Labour Minister found that 137 former timber workers had an association between exposure and symptoms known to be short-term effects of PCP (Occupational Safety and Health Service 1996; Walls et al. 1998). The study was not able to make any analysis of workers who had died or of associations between PCP and rare fatal illnesses such as cancer. This study did however identify low, medium and high exposure groups, and found a significant dose-response relationship between past exposure to PCP and reported symptoms of fever/ sweating, weight loss, persisting fatigue, nausea and neurophysiological dysfunction (Walls et al. 1998). This report also noted that timber treatment workers were exposed to a number of other mixtures since the 
1950s such as CAA (copper, chrome and arsenic solution). The report stated that more evidence was needed before stronger conclusions could be drawn, in particular because the 137 in the sample were voluntary and therefore not a representative sample.

In 1996, due to health concerns raised by workers at timbermill plants the Engineering, Printing and Manufacturing Union (EPMU) set up an exposure register. The purpose of this register was to identify exposed workers and assist them in making ACC claims (Bandaranayake et al. 1999).

A survey in 1999 of the 79 workers on the register found that they experienced an array of conditions including mood swings, breathing difficulties, persistent headaches and memory difficulties. In addition, over a third suffered from chronic diarrhoea, nausea and chronic dizziness. Three of the workers had cancer. Most of the workers suffered from a combination of symptoms (Bandaranayake et al. 1999). Many workers experienced symptoms at relatively low levels of exposure to PCPs. The report found that $72 \%$ of the workers were unclear about how to make a claim to ACC for PCP related problems.

The outcomes for the timbermill workers has not been a ministerial report as with the ICI firefighters, but an ACC panel of experts was set up after extensive lobbying by the Union. Instead of a Commission being set up to investigate $\mathrm{PCP}$ exposures, ACC developed a new assessment mechanism for such 'gradual' process claims. In the case of chemical poisoning, this meant workers alleging a chemical relationship to their illness had to pass a 'test of poisoning'.

With this test of poisoning, if workers scored nine or more points then they would be compensated. One element in the test of poisoning is that where symptoms can possibly be related to other sources, then they will not gain any 'points' in the test for those symptoms. To illustrate, ACC may accept excessive sweating as specific to PCP poisoning if it has a peculiar smell and rots the clothes. A requirement is also that the workers have to be suffering from the symptoms on the day of examination by the panel. This panel was set up 10 years after PCP stopped being used. Some workers presented to ACC with excessive sweating that in the past had the required peculiar smell and rotted clothes, but now no longer had these characteristics. On this basis the excessive sweating symptoms would not accrue points. The test also awards points if a biological marker can be found for the alleged toxic agent, but ACC do not believe that any such biological markers of poisoning by PCP-dioxins exist.

Of the 34 workers examined by the ACC panel, five were accepted for compensation, but none of the cancer sufferers were. Of these five, so far only one has received an independence allowance, one has been granted medical expenses only, and the other three have yet to be informed of their entitlement.
The test of poisoning has itself sparked debate. The test was developed by a working party from the Royal Australasian College of Physicians on order to identify best practice for the assessment of whether a person's illness could be explained by chemical exposure at work (Gorman and Dryson 1998). This working party noted a number of problems faced by occupational health physicians. These include the lack of information about occupational and environmental toxins, and the lack of information about the actual formulations. The working party also suggested that an 'objective' test of poisoning was required as diagnoses of occupational illness can have adverse effects on patients, as 'the negative health effects, in part, are due to the profound aggravation of morbidity that often accompanies compensation' (Gorman and Dryson 1998, 35).

In effect, this latter argument is a powerful rationale for moving away from a balance of probability approach in the assessment of chemical poisoning, and allows the authors of the test of poisoning to be dismissive of cases that could never pass their test. However, this test of poisoning was not acceptable to all occupational health physicians. One argued that the test of poisoning only worked in those cases where evidence-based measures of toxicity exist, and therefore this makes the formula unnecessary. $\mathrm{He}$ argued that the formula does not work for cases like PCP exposure, and he is 'alarmed to see this formula, which has not been validated, being used by ACC or insurance companies to decline possible occupational disease claims' (Walls 1998).

\section{Discussion}

These two examples give us some interesting insights into the interactions that occur between the state, insurance and science. A lowering of the threshold for proof would provoke the fear that there would be an excessive burden on the funds of the compensation scheme. This conflicts with employers' concerns about minimising the premiums they pay and the state's desire to reduce the costs of business activity. Consequently, a state-insurance scheme greeted as ground breaking and as a workers friend, does, in instances where science cannot give absolute proof, seriously disadvantage victims of industrial sickness.

This relates to two different approaches to the burden of proof. In some jurisdictions, such as Ontario, Canada, work factors are assumed to cause disease unless proved otherwise. In others, such as the UK and New Zealand, it is assumed that the disease is not due to work factors unless proved otherwise, and the standard of proof is set very high (Watterson 1999).

A significant change between the two case studies should also be noted. With the 'test of poisoning' established as the criterion of assessment there in no longer a need to attempt to prove the cause of the illness. All that is required is to accept or reject the hypothesis that a particular chemical agent caused the illness. In the event of a rejection of this hypothesis nothing more needs to be done. With the ICI firefighters, the Commission was set up to 
establish cause, deciding that anxiety was the cause of the symptoms experienced. In order to establish anxiety the Commission could be accused of failing the double standard test (Martin 1997:30). That is, upon examination it is clear that the standards of proof set for identifying anxiety as a cause were very low, whereas the standards of proof were very high for establishing chemical poisoning as causative of symptoms. With the establishment of the test of poisoning, such double standards can no longer be exposed.

The convergence of state and business interests to minimise the cost of accident insurance is made particularly easy when occupational disease is constructed by biomedical discourse as arising from one causative agent (Daykin 1999). The difficulty in establishing cause can easily lead to diseases being discounted.

Of note in these two cases are similar constructions of workers seeking compensation. The test of poisoning working party explicitly states that diagnoses of occupational disease, where such diseases are compensatable, have adverse health effects. The psychiatrist's report on the ICI firefighters had as a basic assumption that claims for compensation are explicitly motivated by financial gain. It appears that the movement away from a balance of probability approach in determining disease causation, and a diagnosis of anxiety in favour of occupational illness, are based on notions of the power of the placebo and the malingering worker. This comes at the expense of workers with genuine illness. Judgements about the malingering worker conceal social and class prejudices, and where the issue of worker compensation is raised these concerns about malingering are heightened (Dembe 1998).

As Daykin (1999: 7) notes 'decisions about such issues as occupational exposure levels and threshold limit values reflect value judgements about acceptable levels of risk and not just the rational application of scientific information'. Such value judgements, as in these case studies, frequently serve the interests of employers, even in a no-fault compensation environment where punitive damages would not accrue to employers.

Although it now seems unlikely that the firefighters will receive any compensation for their suffering, this is not necessarily the case for the timbermill workers. Despite the failure to pass the 'test of poisoning' the Union representing the workers is still lobbying for some form of inquiry into the issue. Comparison with other cases of chemical poisoning illustrates that the efforts to receive compensation can take decades. For example, the compensation for victims of what is considered the worst episode of poisoning in Europe, the contaminated rapeseed case in Spain where approximately 500 people died, took 18 years to resolve (Bosch 1999:1975). The cases of methyl mercury poisoning in Minamata (Thurston 1974) and of asbestos ill-effects (Calhoun and Hiller 1988) suggest that, even after decades of lobbying, claims may still be successful.

\section{Future Research}

These case studies are of cases where there has been active lobbying on the behalf of workers to bring the issue to the attention of ACC and other authorities. There is little research that has looked at the way workers react to signs and symptoms of illness and injury in the workplace. Qualitative studies exploring workers' responses to their working environments, and delineating the sort of issues that confront workers when they deal with workplace hazards (from keyboards to radioactive material!) would provide a fuller understanding of workplace illness and injury.

\section{References}

Accident Compensation Commission (1976) A brief description of the accident compensation scheme operating in New Zealand. Wellington: Accident Compensation Commission.

Barandaranayake, N. Caldwell, B. Connell, F. Dawson, M. Fok, M. Hamilton, S. Kelly, J. Marks, N. Ariff, M.A.M. Sanders, T. and Scott, G. (1999) $P C P$ in the Timber Industry: A Follow-up of Exposed Workers. Wellington: Department of Public Health, Wellington School of Medicine.

Bingham, A. (1992) National Task Group on Site Contamination: Task Brief 5-Dioxin Regulations and Guidelines. Wellington: Ministry for the Environment.

Bosch, X. (1999) Billions in Compensation for Toxic Oil Poisoning Victims. Journal of the American Medical Association. 281: 1975-1976.

Calhoun, C. and Hiller, H. (1988) Coping with Insidious Injuries: The Case of Johns-Manville Corporation and Asbestos Exposure. Social Problems. 32: 162-181.

Daykin, N. (1999) Introduction: Critical Perspectives on Health and Work. Daykin, N. Doyal, L. (Eds.) Health and Work: Critical Perspectives. Basingstoke: Macmillan Press.

Dembe, A. (1998) The Medical Detection of Simulated Occupational Injuries: A Historical and Social Analysis. International Journal of Health Services. 28: 227- 239.

Dew, K. (1999) National Identity and Controversy: New Zealand's Clean Green Image and Pentachlorophenal. Health and Place. 5: 45-57.

Elias, S. Bandaranayake, D. Edwards, I. and Glass, W. (1990) The Health Consequences of the ICI Fire: Report to the Minister of Health on the Health of Firefighters in the Fire at the ICI Riverview 
Store, Mount Wellington, Auckland, 21 December 1984. Wellington: Department of Health.

Glass, W. (1985) Health Consequences of the ICI Fire. Dunedin: University of Otago.

Gorman, D. and Dryson, E. (1998) Diagnosis of Chemical Poisoning: Report of a Working Party Established by the Australasian Faculty of Occupational Madicine, Royal Australian College of Physicians, Auckland, 9 May 1999. New Zealand Medical Journal. 111: 34-37.

Jacques, P. (1992) Some Current Issues: The Trade Union View. Richardson, M (Ed.) Risk Management of Chemicals. Cambridge: Royal Society of Chemistry.

Law Commission, (1988) Personal Injury: Prevention and Recovery: Report on the Accident Compensation Scheme. Wellington: Law Commission.

Martin, B. (1997) Suppresion Stories. Collongong: Fund for Intellectual Dissent.

National Task Group, (1992) Report of the National Task Group Investigating Site Contamination from Use of Timber Treatment Chemicals. Wellington: Ministry for the Environment.

Nelkin, D. and Tancredi, L. (1994) Dangerous Diagnostics: The Social Power of Biological Information. Chicago: University of Chicago Press.

New Zealand Fire Service Commission, (1985) Report of the New Zealand Fire Service Commission on the ICI Fire in Auckland on 21 December 1984 Auckland: New Zealand Fire Services Commission.

Occupational Safety and Health Service, (1996) An Investigation into the Health Effects of Previous Occupational Pentachlorophenol Exposure on Timber Sawmill Employees: A Preliminary Study. New Zealand Medical Journal. 111: 362-4.

Stevenson, P. (1992) The Scandal of the PCP Dumps. Terra Nova. June: 10-15.

Thurston, D. (1974) Aftermath in Minamata. Japan Interpreter: 1: 25-42

Turner, K. (1989) Safety, Discipline and the Manager: Building a Higher Class of Men. Sociology. 33: $611-628$

Walls, C. (1998) Diagnosis of Chemical Poisoning. New Zealand Medical Journal. 111: 258

Walls, C. Glass, G, and Pearce, N. (1998) Health Effects of Occupational Penachlorophenol Exposure in Timber Sawmill Employees: A Preliminary Study New Zealand Medical Journal. 111: $362-4$

Watterson, A. (1999) Why We Still Have 'Old' Epidemics and 'Endemics' in Occpuational Health: Policy and Practise Failures and Some Possible Solutions. Daykin, N. and Doyal, L. (Eds.) Health and Work: Critical Perspectives. Basingstoke: Macmillan.

\section{Author \\ Kevin Dew \\ Lecturer \\ Department of Public Health \\ Wellington School of Medicine \\ University of Otago \\ PO Box 7343 \\ Wellington}

kdew@wsmserver.wnmeds.ac.nz 